\title{
REVIEW
}

Open Access

\section{Worldwide surveillance of self-reported sitting time: a scoping review}

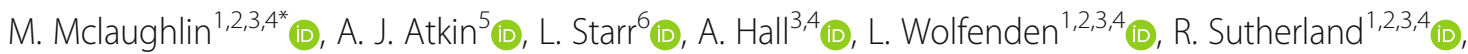

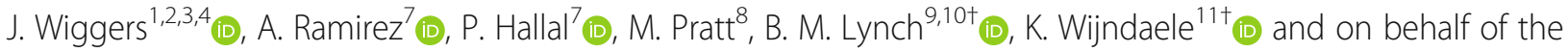 \\ Sedentary Behaviour Council Global Monitoring Initiative Working Group
}

\begin{abstract}
Background: Prolonged sitting time is a risk factor for chronic disease, yet recent global surveillance is not well described. The aims were to clarify: (i) the countries that have collected country-level data on self-reported sitting time; (ii) the single-item tools used to collect these data; and (iii) the duration of sitting time reported across lowto high-income countries.
\end{abstract}

Methods: Country-level data collected within the last 10 years using single-item self-report were included. The sixstage methodology: (1) reviewing Global Observatory for Physical Activity! Country Cards; (2-4) country-specific searches of PubMed, the Demographic and Health Survey website and Google; (5) analysing the Eurobarometer 88.4; and (6) country-specific searches for World Health Organization STEPwise reports.

Results: A total of 7641 records were identified and screened for eligibility. Sixty-two countries (29\%) reported sitting time representing $47 \%$ of the global adult population. The majority of data were from high-income (61\%) and middle income (29\%) countries. The tools used were the International Physical Activity Questionnaire (IPAQ; $n=34)$, a modified IPAQ $(n=1)$ or the Global Physical Activity Questionnaire (GPAQ; $n=27)$. The median of mean daily sitting times was 4.7 (IQR: 3.5-5.1) hours across all countries. Higher-income countries recorded a longer duration of sitting time than lower-income countries ( 4.9 vs 2.7 h).

Conclusions: This study provides an updated collation of countries collecting self-reported sitting time data. The daily sitting time findings should be interpreted cautiously. Current surveillance of sitting time is limited by a lack of coverage. Measures of population sitting time that are valid, feasible and sensitive to change should be embedded within global surveillance systems, to help guide future policy, research and practice.

Trial registration: Not applicable.

Keywords: Sitting time, Sedentary behaviour, Surveillance

\footnotetext{
* Correspondence: Matthew.Mclaughlin1@health.nsw.gov.au

${ }^{+}$Lynch BM and Wijndaele K are co-senior authors.

'School of Medicine and Public Health, University of Newcastle, Newcastle 2308, Australia

${ }^{2}$ Hunter New England Population Health, Locked Bag 10, Wallsend, NSW 2287, Australia

Full list of author information is available at the end of the article
}

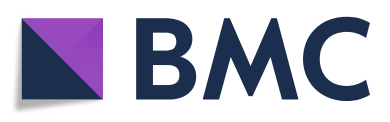

(c) The Author(s). 2020 Open Access This article is licensed under a Creative Commons Attribution 4.0 International License, which permits use, sharing, adaptation, distribution and reproduction in any medium or format, as long as you give appropriate credit to the original author(s) and the source, provide a link to the Creative Commons licence, and indicate if changes were made. The images or other third party material in this article are included in the article's Creative Commons licence, unless indicated otherwise in a credit line to the material. If material is not included in the article's Creative Commons licence and your intended use is not permitted by statutory regulation or exceeds the permitted use, you will need to obtain permission directly from the copyright holder. To view a copy of this licence, visit http://creativecommons.org/licenses/by/4.0/. The Creative Commons Public Domain Dedication waiver (http://creativecommons.org/publicdomain/zero/1.0/) applies to the data made available in this article, unless otherwise stated in a credit line to the data. 


\section{Background}

Sedentary behaviour is characterised as any waking behaviour at an intensity $\leq 1.5$ METs in a sitting or reclining posture [1]. Sitting time is a sub-component of sedentary behaviour and a common measure of sedentary behaviour [2]. Sedentary behaviour is associated with a range of adverse health outcomes, including, but not limited to: all-cause, cardiovascular and cancer mortality, type 2 diabetes and depression [3-10]. In particular, the combination of high amounts of sedentary behaviour and low amounts of moderate-to-vigorous physical activity is associated with all-cause and cardiovascular mortality [3, 7], As such, the World Health Organization is currently in the process of revising the 2010 global physical activity guidelines to include recommendations related to sedentary behaviour across all age groups [11].

Public health surveillance systems are used to identify emerging health threats, monitor changes in health and risk factors, guide programs to target threats and prioritise public health action [12]. Global surveillance data enables cross-country comparisons, and can be used to assess the influence of national policy initiatives on health risks and diseases $[12,13]$. Such systems are recommended by the United Nations and World Health Organization and are increasingly being applied to noncommunicable disease risks $[14,15]$. Good surveillance systems can provide comparable actionable data and are characterised by valid, low cost and feasible assessments of risk in populations [12].

Sitting time is a common measure of sedentary behaviour [2]. Device-based measures of sitting time are more valid than self-reported sitting time, but are high cost, burdensome for participants and not yet widely used [2, 16]. Although people tend to under-report sitting time (1.4-2.1 $\mathrm{h}$ less than device-based), there are several selfreport measures that have evidence of reliability and validity [2, 16-22] providing a potentially low cost, feasible option for use in national surveillance systems [14]. One promising method is to measure how long seated activities are undertaken (e.g. time spent driving, watching television), rather than asking how long someone has spent sitting [23]. However, single-item measurement of total sitting time may remain important for population surveillance as it is highly feasible.

Given the adverse impacts of sedentary behaviour, it is important to measure this risk factor globally. Collated data on self-reported physical activity from 168 countries, collected within the last 20 years, are available [24]. However, a comprehensive collation of sedentary behaviour data collected within the last 10 years does not currently exist. To our knowledge, only one previous study has collated data across countries globally on selfreported sitting time [9]. Rezende et al. found that adults from across 54 countries sit on average $4.7 \mathrm{~h}$ /day (282 min/day, weighted mean by country population) [9]. They used data from 2002 to 2011 collected from three main sources (Eurobarometer, World Health Organisation STEPwise approach to Surveillance (STEPS) and the International Prevalence Study) [14, 25, 26]. They additionally searched scientific databases yielding only five additional sources [9]. Other studies have collated smaller data sets, for example a 20-country comparison [26] or European-only data [25, 27].

To inform future global surveillance of sedentary behaviour, this study addressed the following three key questions: (i) What countries have collected countrylevel data on self-reported sitting time? (ii) What singleitem self-report tools have countries used to collect such data? (iii) What is the duration of self-report, countrylevel sitting time by low-, lower-middle, upper-middle and high-income countries?

\section{Methods}

This scoping review is reported in accordance with the PRISMA-ScR checklist (Supplementary file 1) [28]. The methods described here were outlined in a methods manual [29], which was executed through the Global Sedentary Behaviour Monitoring Initiative. This initiative is led by the Sedentary Behaviour Council (SBC) and Global Observatory for Physical Activity (GoPA!) Council of the International Society for Physical Activity and Health (ISPAH). The search strategy of the Global Sedentary Behaviour Monitoring Initiative included other outcomes not reported here.

\section{Eligibility criteria}

We excluded studies where data were collected more than 10 years before the initial search date (May 2018), to ensure the recency of data. We excluded studies limited to a single sex to improve data representativeness. We included studies in English. We additionally sought translations of reports in languages other than English for stage 5 of the search strategy (Fig. 1). We included both published and unpublished data from scientific and grey literature. The outcomes of interest for this report were: (i) countries reporting country-level data on selfreported sitting time collected in the last 10 years (2008-2018), in an adult population (age 15+); and (ii) the single-item self-report measure used to collect these data; (iii) the minutes of total daily sitting time reported within these data. We excluded data from multi-item self-report tools and device-measured sedentary behaviour, due to issues with harmonisation and limited availability of country-level data [2, 22]. 


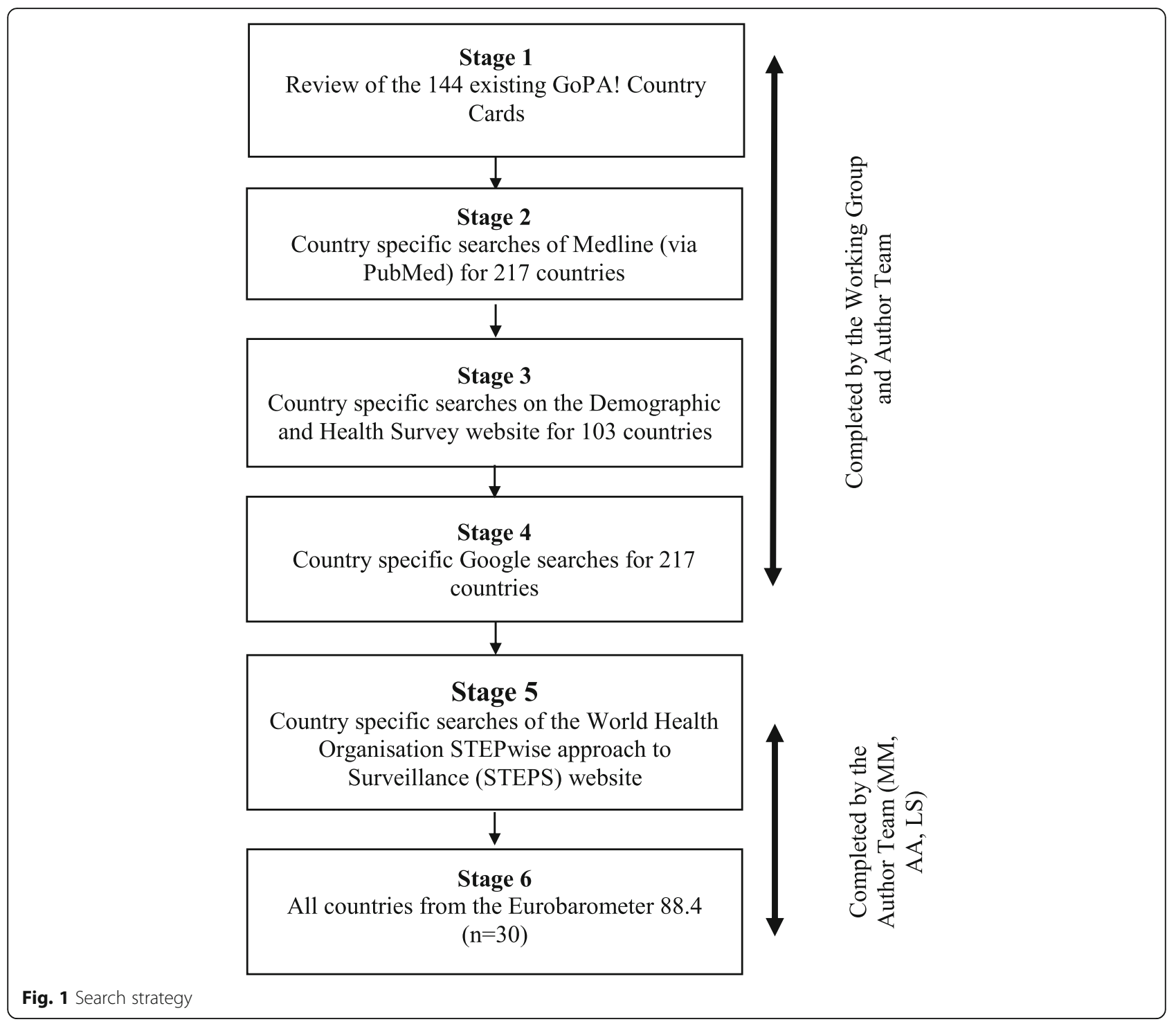

\section{Classification of countries}

In alignment with the GoPA! methodology applied to monitoring physical activity surveillance [30], we searched for data across 217 countries. Starting with a list of 215 countries derived from the World Bank [31], we subsequently split the United Kingdom into the four home nations (England, Scotland, Wales, and Northern Ireland), and combined information from China and Taiwan. For analyses, we classified countries by income level, using the 2020 World Bank's classification [31]. We subsequently consolidated to 215 countries, as described in stage 6 below (Fig. 1).

\section{Search strategy}

The search strategy consists of six stages (Fig. 1).

Stages 1-4 were completed by a Working Group and members of the Author team (MM, AR, AA) between
May 2018 and December 2018. We recruited a Working Group of volunteers $(n=25)$ via email (March 2018) from the membership of the ISPAH Sedentary Behaviour Council. Each Working Group member was trained to conduct the searches through videoconferencing (April 2018) by one author (MM), and provided with a methods manual detailing the search strategy [29]. Throughout the search process, MM and AA assisted the Working Group to conduct searches via email and videoconferencing. Working Group members were allocated to countries $(n=9-14)$. Where possible, the Working Group members were allocated to countries from their region of residence, and surrounding countries.

\section{Stage 1}

The Working Group identified the data source cited for the physical activity prevalence estimate in each of "The 
1st Physical Activity Almanac" GoPA! country cards $(n=139)$, as well as for five additional country cards added to the website since the launch of the first Almanac. These sources $(n=144)$ were then searched for relevant information on sitting time.

\section{Stage 2}

Country-specific searches of Medline were made through PubMed for each country, using the search terms listed in Supplementary file 2. All records were screened by the respective member of the Working Group.

\section{Stage 3}

The Demographic and Health Survey website contains data on health from country-level surveys. Countryspecific searches were made for countries listed on its website $(n=105)$.

\section{Stage 4}

Seven country-specific Google searches were made for each country using the terms listed in Supplementary file 2, which were entered in 'www.Google.com/ncr' to avoid country redirect differences in country-specific versions of Google. The first 20 titles were reviewed for each respective search.

Additional studies were also recommended by the Working Group's collective knowledge and via snowballing from identified studies.

\section{Stages 5-6}

Three authors (MM, LS, AA) conducted stage 5-6.

\section{Stage 5}

The World Health Organisation STEPwise approach to Surveillance (STEPS) is a standardised framework of data collection for countries [14]. For all countries, country-specific searches of the World Health Organisation STEPwise approach to Surveillance (STEPS) website were conducted. Where reports were not in English, translations were sought.

\section{Stage 6}

The Eurobarometer is a periodical survey that takes place in European countries. The most recent survey including sitting time data was the Special Eurobarometer 472 (Wave 88.4, December 2017) in 28 countries (30 constituencies) $[20,21]$. More information on the Eurobarometer series can be found at http://www.gesis.org/ en/eurobarometer/survey-series/standard-special-eb/.

\section{Data management}

From search stages 1-4, each member of the Working Group collated sources of interest into a country- specific Endnote file (or equivalent). Subsequently, the Working Group provided recommendations of the most appropriate data sources using a form (Supplementary file 3) based on the outcomes of interest. Where there was more than one eligible source for a country, recommendations were made based on the following hierarchical criteria:

(i). Sample representativeness: priority was placed on studies where the sampling procedure was intended to provide data representative of the whole country. Samples across geographic areas of a country were preferred to samples restricted to specific areas of a country e.g., a single state or city (termed by the World Health Organisation as "sub-national").

(ii). Recency: year of data collection.

Data sources derived from search strategy stages 5 and 6 were combined with recommendations made by the Working Group. Figure 2 shows the flowchart of the review process.

One researcher $(\mathrm{MM})$ then screened all data sources from stages 5-6 and recommendations from the Working Group for inclusion. A total of 145 data sources were recommended by the working group from stages $1-4$. A single data source was selected for each country based on the aforementioned hierarchical criteria.

\section{Data extraction}

Data extraction is described according to each aim.

(i) What countries have collected country-level data on self-report sitting time in the last 10 years?

The country name, years of data collection and year of publication were extracted from the data source. The corresponding World Health Organisation region [32], World Bank Income Classification [31] and human population in 2015 [33] were then assigned.

(ii) What single-item self-report tools have countries used to collect country-level data on sitting time?

The instrument used to assess self-reported sitting time was extracted from the report.

(iii) What amount of sitting time is reported according to low-, lower-middle, upper-middle and high-income countries?

The sample size (n), age range of the sample, mean, standard deviation (SD) and 95\% confidence intervals (CI) were extracted from available sources for sitting time. However, a number of data transformations were required due to the unavailability of such data. The full list of data transformations are provided in Supplementary file 4. For Stage 6 of the search, Eurobarometer 88.4 data were downloaded. Firstly, the two constituencies of East and West Germany data were combined. The United Kingdom home nations' (England, Scotland, 


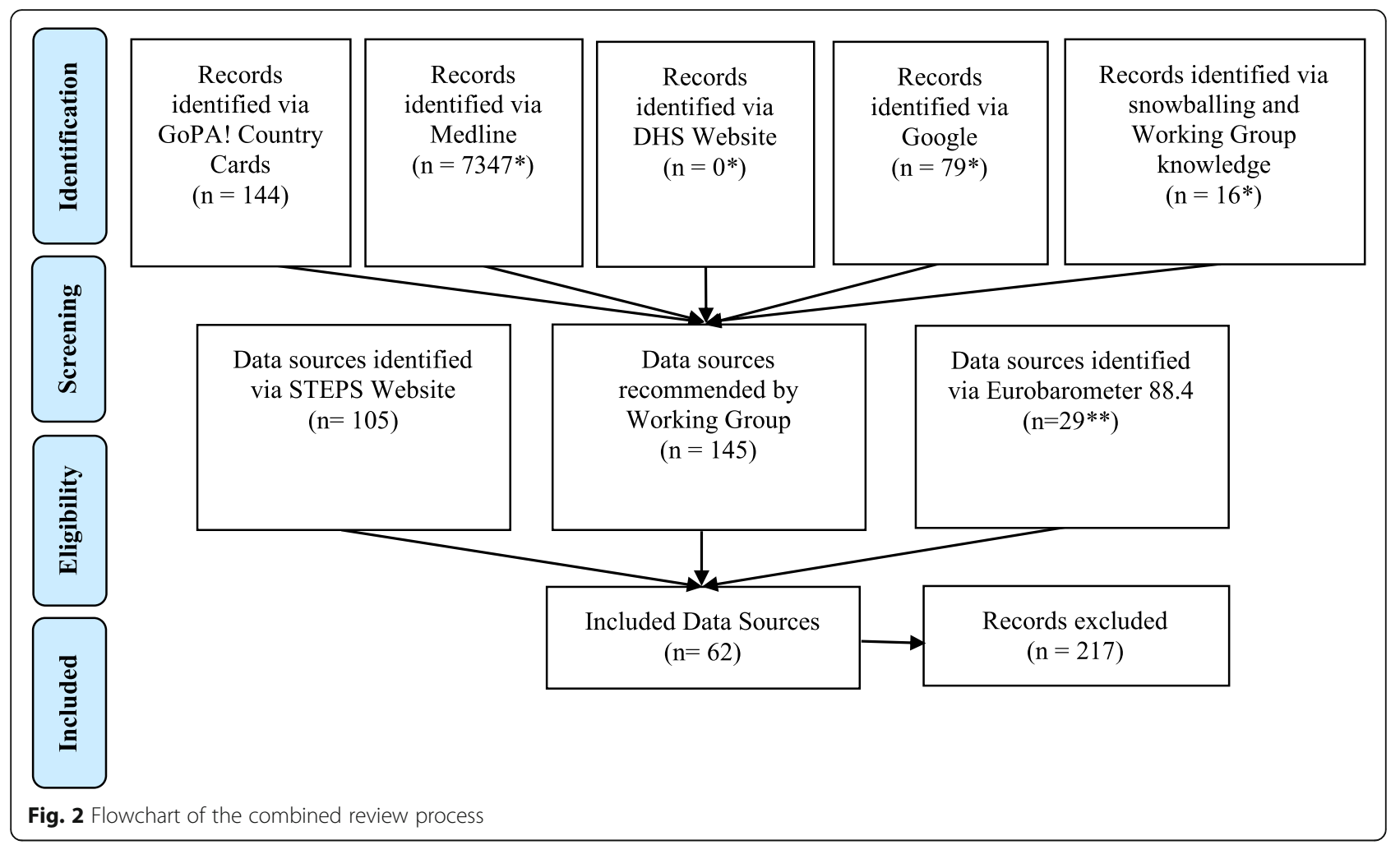

Wales and Northern Ireland) data were extracted directly as Great Britain (England, Scotland and Wales) and Northern Ireland respectively. Thus, the total number of possible countries to be searched reduced from 217 to 215 .

\section{Statistical analysis}

Data for aims 1 and 2 were extracted directly. For aim 3, sitting time duration was not always readily available, as this outcome was sometimes reported as categorical rather than continuous data. Therefore, we used the midpoint scoring method to estimate the mean and SD [25]. For open-ended categories (e.g. $>6 \mathrm{~h}$ ) the highest category was truncated at 960 min based on the assumption that the average healthy adult will be awake for at least $16 \mathrm{~h}$ per day [19, 34]. For the lowest category (e.g. $<5 \mathrm{~h}$ ) a lower value of 0 was used. Countries for which this transformation applied included: Saudi Arabia, South Korea and the Eurobarometer 88.4 countries. For studies that reported data separately by sex, a pooled mean estimate and 95\% CI were calculated using the metan package in STATA. When the median and/or interquartile ranges were presented, recommended formulae were used to transform these values into mean and SD [35].

\section{Results}

A total of 7641 records were identified and screened for eligibility. (i) What countries have collected country-level data on self-report sitting time in the last 10 years?

Sixty-two countries had eligible data on sitting time (29\% of all global countries). These countries represent $47 \%$ of the global population in 2015 [31]. The majority of countries were from middle-income $(29 \%)$ and highincome economies (61\%). Data were collected from 2008 to $2012(n=19)$ and from 2013 to $2018(n=43)$. The findings for each country are listed in Table 1 . Half of all countries were from the European region (EURO). Figure 3 shows a map of which countries have collected data. Table 2 summarises the distribution of countries across the World Health Organization geographic regions. Few data sources were identified across South America, Africa and Australasia.

(ii) What self-report tools have been used to collect country level data on sitting time?

Most studies employed the International Physical Activity Questionnaire (IPAQ) $(n=34)$ or the Global Physical Activity Questionnaire (GPAQ) $(n=27)$ to collect data on sitting time $[18,20]$. One survey (United States) used an adapted version of the IPAQ $(n=1)$. The IPAQ (both short and long version) uses the single item, "How much time do you spend sitting on a usual day? This may include time spent at a desk, visiting friends, studying or watching television". The GPAQ contains the single item question: "How much time do you usually spend sitting or reclining on a typical day?" and this is prefaced 


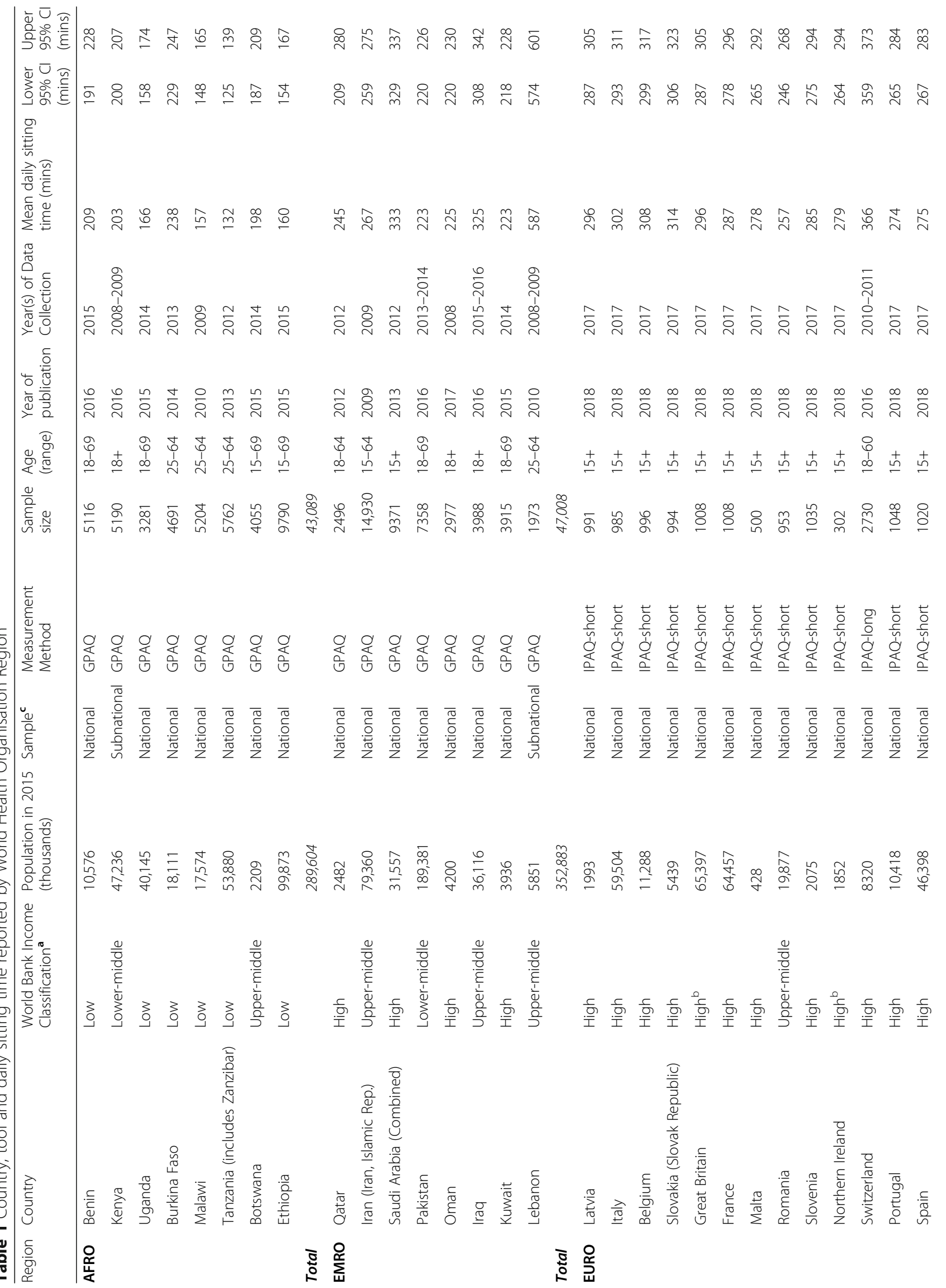




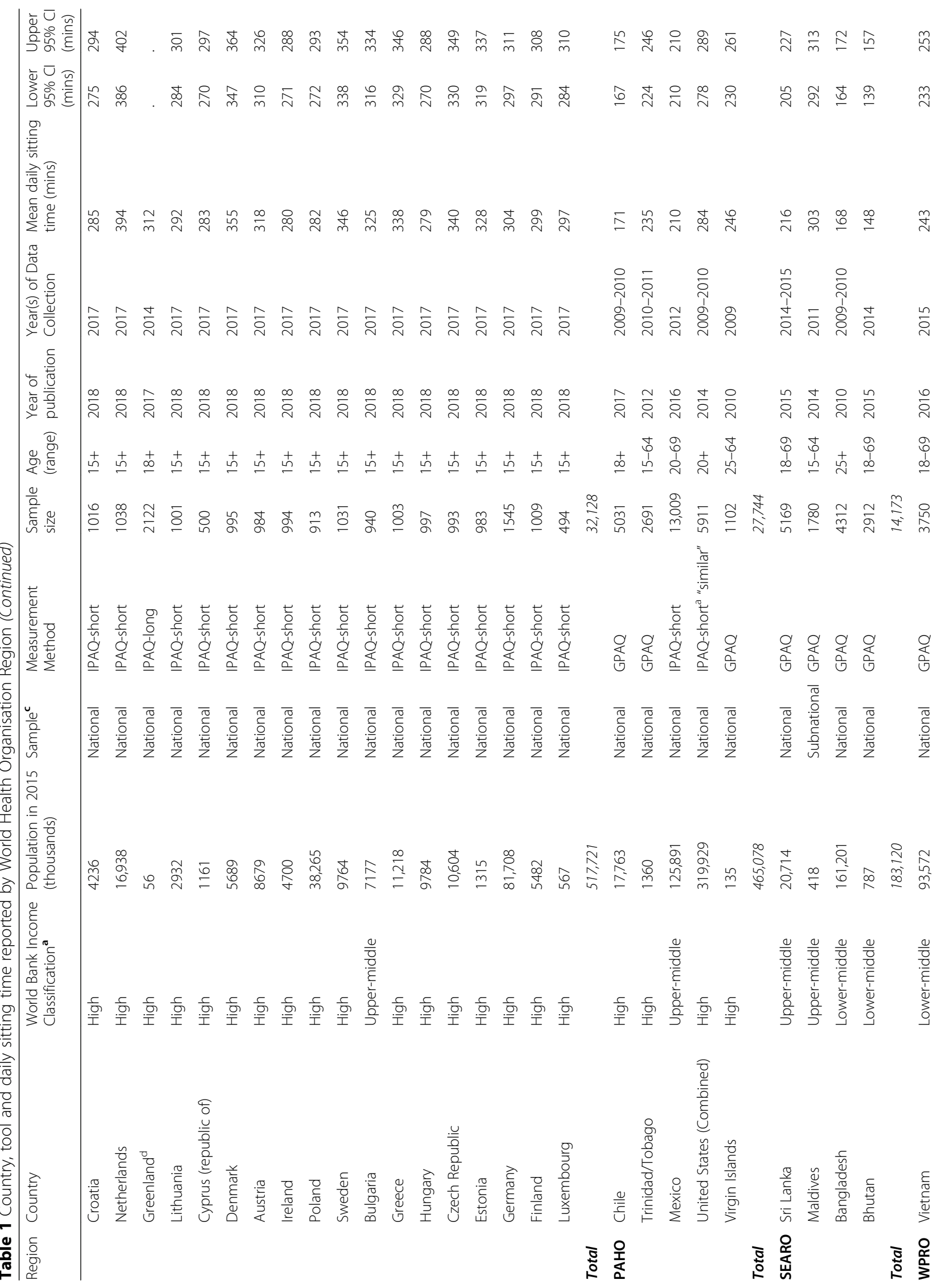




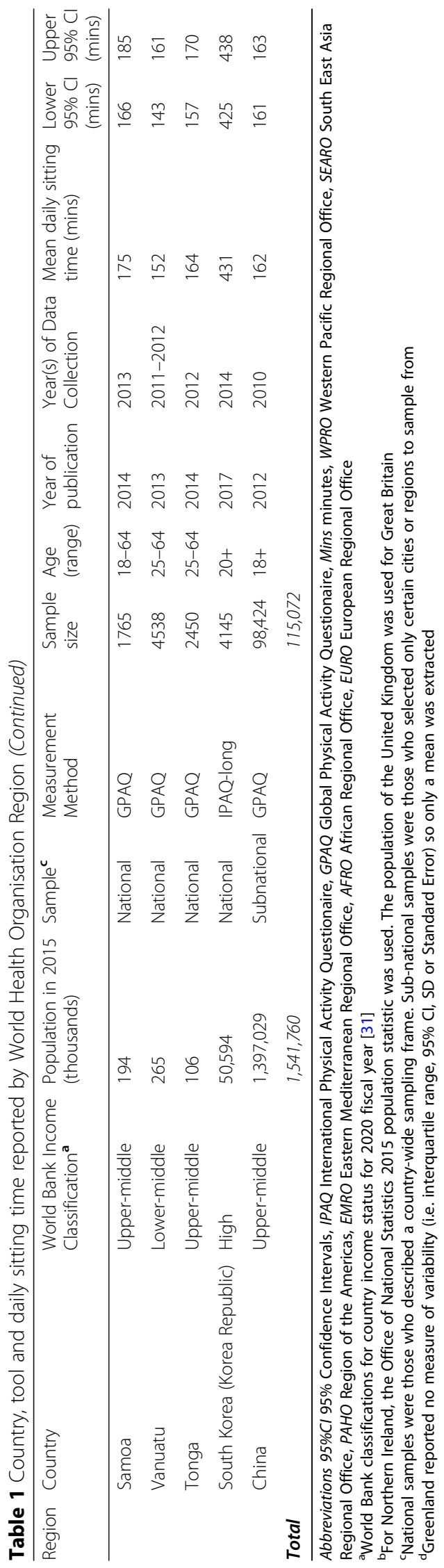




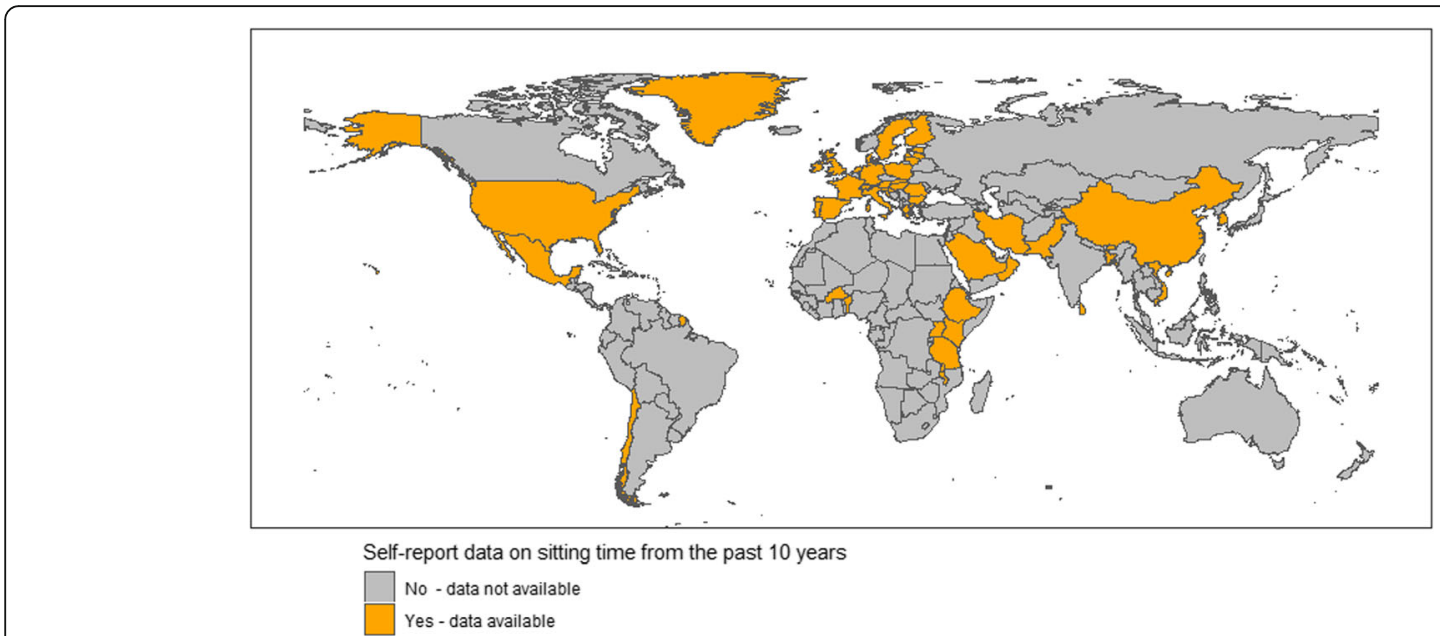

Fig. 3 Geographical distribution of countries with a country-level self-report sitting time survey in the last 10 years

by "The following question is about sitting or reclining at work, at home, getting to and from places, or with friends including time spent sitting at a desk, sitting with friends, traveling in car, bus, train, reading, playing cards or watching television, but do not include time spent sleeping" [18]. Table 1 outlines the measure used by the countries included in the study.

The Eurobarometer measures sitting time using the IPAQ. The World Health Organisation STEPwise approach to surveillance (STEPS) measures sitting time using the GPAQ [18].

(iii) What is the duration of sitting time reported by low, lower-middle, upper-middle and high-income countries?

The median of mean sitting time from all countries $(n=62)$ was $279 \mathrm{~min}$ (IQR: $210-304)$, equivalent to $4.7 \mathrm{~h}$ daily. The median of mean sitting times from high-income countries was almost double that of low-income countries $(4.9$ vs $2.7 \mathrm{~h})$. Table 2 outlines sitting time by World Bank Income classification. World Bank Income Classifications are provided in Supplementary file 5.

Table 2 Median of mean sitting times by country income classification

\begin{tabular}{lll}
\hline $\begin{array}{l}\text { Country Income } \\
\text { (World Bank } \\
\text { Classification }^{\text {a }} \text { ) }\end{array}$ & Countries (n) & $\begin{array}{l}\text { Median of mean } \\
\text { sitting times } \\
\text { median hours (IQR) }\end{array}$ \\
\hline Low-income & 6 & $2.7(2.6-3.3)$ \\
Lower-middle income & 6 & $3.1(2.6-3.6)$ \\
Upper-middle income & 12 & $3.9(3.2-5.1)$ \\
High-income $^{\mathbf{b}}$ & 38 & $4.9(4.7-5.3)$ \\
Total & 62 & $4.7(3.5-5.1)$ \\
\hline
\end{tabular}

${ }^{a}$ World Bank classifications for country income status for 2020 fiscal year [31] ${ }^{b}$ For Great Britain and Northern Ireland respectively, the World Bank classification used was for the United Kingdom

\section{Discussion}

This study reviewed all countries globally and collated self-reported country-level data on sitting time. We found just 62 countries (29\%) reporting sitting time data in the last 10 years, most of which were high-income countries (61\%). Of those countries who did report data, the median of mean daily sitting times was 4.7 (IQR: 3.5-5.1) hours per day. Persons from higher-income countries tended to report sitting longer than those from lower-income countries, with each World Bank Income Classification group from low to high reporting progressively greater sitting times. Most data came from just two sources, the Eurobarometer [25] and the World Health Organisation STEPwise approach to Surveillance (STEPS) Reports [14].

The results of this review should be considered in the context of its limitations. To facilitate comparison between countries, we reduced heterogeneity by restricting to single-item self-report sitting time measures. Such measures have poor accuracy and potentially a lack of validity [16, 22]. Self-report measurement has been found to underreport daily sitting time by $1.4-2.1 \mathrm{~h}$ compared with device based measurement [22]. While we used extensive search methods to find relevant data, we expect that some countries have collected data, but have not made these available online. This may be particularly true of countries involved with World Health Organisation STEPwise approach to Surveillance (STEP S) surveillance, who have not made available their reports on the World Health Organisation website. While we were able to seek language translations for STEPWise data (Stage 5), it's also expected that some countries may have reported data in languages other than English. It was a pragmatic decision to search for studies in English. Limiting to English is consistent with the scoping review process, however its likely data from countries where English is not the first language were missed. 
Our study identified data from 62 countries' from 2008 to 2018, where most data were collected within the latter half of this period. This updates the previous collation of sitting time data from Rezende et al. (2016) who collated 54 countries' data from 2002 to 2011 [9]. The overall sitting time reported in our study and those reported by Rezende et al. are similar. Specifically, Rezende et al. reported a country population-weighted mean sitting time of $4.7 \mathrm{~h}$ per day and a median of mean sitting time of $5 \mathrm{~h}$ per day, compared with the present study, which found a median of mean sitting time across all countries of $4.7 \mathrm{~h}$ per day [9]. Rezende et al.'s sample represented a quarter of the global adult population, whereas the current study represents half of the global adult population (47\%). Both studies identified a paucity of data from Africa and Asia, but Rezende et al. included older data from South America.

Variations in sitting time across countries were large, ranging from $2.2-9.5 \mathrm{~h}$ per day (IQR: $3.5-5.1 \mathrm{~h}$ ). Highincome countries reported sitting almost double that of low-income countries ( 4.9 vs $2.7 \mathrm{~h}$ per day), perhaps because higher-income countries have a higher proportion of the population employed in sedentary occupations [36]. As countries urbanise, and occupations become more sedentary (e.g., greater share of jobs are in service related industries rather than manufacturing/agriculture), it is possible that people in these countries will become more sedentary and sit for longer [36]. In some countries, there may also be underlying social and cultural practices that lead to high sedentary time during leisure [37].

Compared with other risk factors for chronic disease, global coverage of sitting time prevalence data is low ( $47 \%$ of the global population). For example, a recent collation of physical activity data represents $96 \%$ of the global population [24] and a collation of smoking prevalence has been generated in $90 \%$ of countries [38]. Given the public health impact of high amounts of sitting time $[4,5,7,9,10]$, the broader global adoption of such sitting time surveillance systems seems warranted. Public health surveillance systems can help inform action, guide public health interventions, evaluate public policy and advocate for policy change [12], which will be required to change and monitor sitting time prevalence. The predominant existing items used in country-level surveillance, the IPAQ and GPAQ, are low-cost and feasible. A stronger global surveillance system will use more accurate measures of sitting time that remain feasible, and have demonstrated sensitivity to change $[16,17,22$, 23]. The Global Observatory for Physical Activity (GoPA!) has begun establishing a physical activity surveillance system that may be a platform to embed sedentary behaviour data collation [30].

\section{Conclusion}

This study provides an updated collation of self-report sitting time globally. The daily sitting time findings should be interpreted cautiously. Sitting time data were collected in 62 of 215 countries, representing $47 \%$ of the global adult population. Daily sitting time was on average $4.7 \mathrm{~h}$. There was particularly a lack of data in low- and middle-income countries, but data that were available suggested they reported less daily sitting time than higher-income countries. There is an opportunity to improve surveillance efforts by developing and using improved measures of sitting time and increasing global coverage of countries. Doing so will be crucial to guide future policy, research and practice in managing sedentary behaviour as a risk factor for chronic disease [12], and may be embedded within wider surveillance systems such as The Global Observatory for Physical Activity (GoPA!) [30] and World Health Organisation STEPwise approach to Surveillance (STEPS) [14]. The current data, limited as they are, are being used to inform the second set of Country Cards produced by the Global Observatory for Physical Activity (GoPA!).

\section{Supplementary information}

Supplementary information accompanies this paper at https://doi.org/10. 1186/s12966-020-01008-4.

\section{Additional file 1: Supplementary file 1. PRISMA Scoping Review Checklist. \\ Additional file 2: Supplementary file 2. Search Terms used in Stages 2 and 4.}

Additional file 3: Supplementary file 3. Recommendation Form used by the Working Group.

Additional file 4: Supplementary file 4. Transformation formulas used to estimate the mean and standard deviation.

Additional file 5: Supplementary file 5. The World Bank country classifications.

\section{Abbreviations}

IPAQ: International Physical Activity Questionnaire; GPAQ: Global Physical Activity Questionnaire; GoPA!: Global Observatory for Physical Activity; SBC: Sedentary Behaviour Council; ISPAH: International Society for Physical Activity and Health; STEPS: STEPwise approach to Surveillance

\section{Acknowledgements}

GROUP AUTHORSHIP: The named authors present the study on behalf of the Sedentary Behaviour Council Global Monitoring Initiative Working Group, which comprises: Saiful Adli, Paul A. Gardiner, Ciaran B. Doyle, Angela Meadows, Ruth M. Mabry, Alberto Florez Pregonero, Kabir P. Sadarangani, Nyssa T. Hadgraft, Terry Boyle, Nicolas Aguilar Farias, Jacqueline L. Mair, Siosaia F. Hafoka, Gregore Iven Mielke, Selina Khoo Phaik Lin, Vienna R. McLeod, Chathuranga Ranasinghe, Paul C. Storning, Ing-Mari Dohrn, Falk Müller-Riemenschnieder, Lyutha Al Subhi, Anne Chu Hin Yee, Mayuri Gad, Adilson Marques, Elli Kontostoli.

\section{Authors' contributions}

MM, AA, BML, KW, AR, PH and MP designed the Global Monitoring Initiative and the search strategy. MM trained the Working Group who executed the search strategy. MM and LS extracted data. AA, AH and MM analysed the data. MM drafted the manuscript. MM, AA, BML, KW, LS, AH, LW, JW, RS, AR, $\mathrm{PH}$ and MP provided critical feedback on manuscript drafts. All authors and 
the Working Group approved the final manuscript. The authors would also like to thank François Boudrias, Peter Butler, Min Ng, Soren Brage and Antonia Ciurea for language translations.

\section{Funding}

There was no specific funding for this work. KW was supported by the UK Medical Research Council [grant number MC_UU_12015/3]

\section{Availability of data and materials}

The datasets used during the current study are available within the manuscript in full. Additional queries may be directed to the corresponding author.

\section{Ethics approval and consent to participate}

Not applicable.

\section{Consent for publication}

Not applicable.

\section{Competing interests}

The authors declare that they have no competing interests.

\section{Author details}

${ }^{1}$ School of Medicine and Public Health, University of Newcastle, Newcastle 2308, Australia. ${ }^{2}$ Hunter New England Population Health, Locked Bag 10, Wallsend, NSW 2287, Australia. ${ }^{3}$ Hunter Medical Research Institute, Newcastle, NSW 2300, Australia. ${ }^{4}$ Priority Research Centre in Health Behaviour, University of Newcastle, Newcastle, NSW, Australia. ${ }^{5}$ Faculty of Medicine and Health Sciences, University of East Anglia, Norwich, UK. ${ }^{6}$ Warwick Medical School, University of Warwick, Coventry, West Midlands, UK. ${ }^{7}$ School of Medicine, Los Andes University, Bogotá, Colombia. ${ }^{8}$ University of California San Diego, San Diego, California, USA. ${ }^{9}$ Cancer Epidemiology Division, Cancer Council Victoria, Melbourne, Victoria, Australia. ${ }^{10}$ Centre for Epidemiology and Biostatistics, Melbourne School of Population and Global Health, The University of Melbourne, Melbourne, Victoria, Australia. ${ }^{11} \mathrm{MRC}$ Epidemiology Unit, University of Cambridge School of Clinical Medicine, Cambridge, Cambridgeshire, UK.

Received: 23 April 2020 Accepted: 30 July 2020

\section{Published online: 03 September 2020}

\section{References}

1. Tremblay MS, Aubert S, Barnes JD, Saunders TJ, Carson V, Latimer-Cheung $A E$, et al. Sedentary behavior research network (SBRN) - terminology consensus project process and outcome. Int J Behav Nutr Phys Act. 2017; 14(1):75..

2. Healy GN, Clark BK, Winkler EA, Gardiner PA, Brown WJ, Matthews CE. Measurement of adults' sedentary time in population-based studies. Am J Prev Med. 2011;41(2):216-27.

3. Ekelund U, Tarp J, Steene-Johannessen J, Hansen BH, Jefferis B, Fagerland MW, et al. Dose-response associations between accelerometry measured physical activity and sedentary time and all cause mortality: systematic review and harmonised meta-analysis. BMJ. 2019;366:14570.

4. Biswas A, Oh Pl, Faulkner GE, Bajaj RR, Silver MA, Mitchell MS, et al. Sedentary time and its association with risk for disease incidence, mortality, and hospitalization in adults: a systematic review and meta-analysis. Ann Intern Med. 2015;162(2):123-32

5. Pandey A, Salahuddin U, Garg S, Ayers C, Kulinski J, Anand V, et al. Continuous dose-response association between sedentary time and risk for cardiovascular disease: a meta-analysis. JAMA Cardiol. 2016;1(5):575-83.

6. Zhai $L$, Zhang $Y$, Zhang D. Sedentary behaviour and the risk of depression: a meta-analysis. Br J Sports Med. 2015;49(11):705-9.

7. Stamatakis E, Gale J, Bauman A, Ekelund U, Hamer M, Ding D. Sitting time, physical activity, and risk of mortality in adults. J Am Coll Cardiol. 2019; 73(16):2062.

8. Bailey DP, Hewson DJ, Champion RB, Sayegh SM. Sitting time and risk of cardiovascular disease and diabetes: a systematic review and meta-analysis. Am J Prev Med. 2019;57(3):408-16.

9. Rezende LFM, Sá TH, Mielke GI, Viscondi JYK, Rey-López JP, Garcia LMT. Allcause mortality attributable to sitting time: analysis of 54 countries worldwide. Am J Prev Med. 2016;51(2):253-63.
10. Patterson R, McNamara E, Tainio M, de Sá TH, Smith AD, Sharp SJ, et al. Sedentary behaviour and risk of all-cause, cardiovascular and cancer mortality, and incident type 2 diabetes: a systematic review and dose response meta-analysis. Eur J Epidemiol. 2018;33(9):811-29.

11. Organisation WH. Public consultation on the draft WHO Guidelines on physical activity and sedentary behaviour for children and adolescents, adults and older adults. 2020. Available from: https://perma.cc/9ZFD-G6XB.

12. Groseclose SL, Buckeridge DL. Public health surveillance systems: recent advances in their use and evaluation. Annu Rev Public Health. 2017;38:57-79.

13. Kroll M, Phalkey RK, Kraas F. Challenges to the surveillance of noncommunicable diseases - a review of selected approaches. BMC Public Health. 2015;15(1):1243.

14. World Health Organization. STEPS: A framework for surveillance. Geneva: World Health Organization; 2003.

15. United Nations. Prevention and control of noncommunicable diseases. Outcomes of the high-level meeting of the general assembly on the prevention and control of non-communicable diseases and the first global ministerial conference on healthy lifestyles and noncommunicable disease control. A65/6. New York: United Nations; 2012.

16. Dall P, Coulter E, Fitzsimons C, Skelton D, Chastin S. TAxonomy of selfreported sedentary behaviour tools (TASST) framework for development, comparison and evaluation of self-report tools: content analysis and systematic review. BMJ Open. 2017;7(4):e013844.

17. Chastin SFM, Culhane B, Dall PM. Comparison of self-reported measure of sitting time (IPAQ) with objective measurement (activPAL). Physiol Meas. 2014:35(11):2319-28.

18. Armstrong T, Bull F. Development of the World Health Organization global physical activity questionnaire (GPAQ). J Public Health. 2006;14(2):66-70.

19. Busschaert C. Reliability and validity of three questionnaires measuring context-specific sedentary behaviour and associated correlates in adolescents, adults and older adults. Int J Behav Nutr Phys Act. 2015;12:117.

20. Craig CL, Marshall AL, Sjöström M, Bauman AE, Booth ML, Ainsworth BE, et al. International physical activity questionnaire: 12-country reliability and validity. Med Sci Sports Exerc. 2003;35(8):1381-95.

21. Rosenberg DE, Bull FC, Marshall AL, Sallis JF, Bauman AE. Assessment of sedentary behavior with the international physical activity questionnaire. J Phys Act Health. 2008:5(Suppl 1):S30-44.

22. Prince SA, Cardilli L, Reed JL, Saunders TJ, Kite C, Douillette K, et al. A comparison of self-reported and device measured sedentary behaviour in adults: a systematic review and meta-analysis. Int J Behav Nutr Phys Act. 2020:17(1):31.

23. Gardner B, Flint S, Rebar AL, Dewitt S, Quail SK, Whall H, et al. Is sitting invisible? Exploring how people mentally represent sitting. Int J Behav Nutr Phys Act. 2019;16(1):85.

24. Guthold R, Stevens GA, Riley LM, Bull FC. Worldwide trends in insufficient physical activity from 2001 to 2016: a pooled analysis of 358 populationbased surveys with 1.9 million participants. Lancet Glob Health. 2018;6(10): e1077-e86.

25. Loyen A. European sitting championship: prevalence and correlates of selfreported sitting time in the 28 European Union Member States. PLOS one. 2016;11:e0149320

26. Bauman A, Ainsworth BE, Sallis JF, Hagströmer $M$, Craig $C L$, Bull FC, et al. The descriptive epidemiology of sitting: a 20-country comparison using the international physical activity questionnaire (IPAQ). Am J Prev Med. 2011; 41(2):228-35.

27. Milton K, Gale J, Stamatakis E, Bauman A. Trends in prolonged sitting time among European adults: 27 country analysis. Prev Med. 2015;77:11-6.

28. Tricco AC, Lillie E, Zarin W, O'Brien KK, Colquhoun H, Levac D, et al. PRISMA extension for scoping reviews (PRISMA-SCR): checklist and explanation. Ann Intern Med. 2018;169(7):467-73.

29. Sedentary Behaviour Council and Global Observatory for Physical Activity of the International Society for Physical Activity and Health. Methods Manual SBC-GoPA! Global Monitoring Inititative. 2017. Available from: http://new. globalphysicalactivityobservatory.com/.

30. Ramirez Varela A, Pratt M, Powell K, Lee I-M, Bauman A, Heath G, et al. Worldwide surveillance, policy, and research on physical activity and health: the global Observatory for Physical Activity. J Phys Act Health. 2017;14(9): 701-9.

31. The World Bank. World Bank Country and Lending Groups. 2019. Available from: https://datahelpdesk.worldbank.org/knowledgebase/articles/906519. 
32. World Health Organisation. Alphabetical List of WHO Member States: World Health Organisation; 2020. Available from: https://www.who.int/choice/ demography/by_country/en/.

33. The World Bank. Population, total: The World Bank; 2020. Available from: https://data.worldbank.org/indicator/SP.POP.TOTL?end=2015\&start=2015.

34. Hendriksen I. Longitudinal relationship between sitting time on a working day and vitality, work performance, Presenteeism, and sickness absence. JOEM. 2016;58:784-9.

35. Wan X. Estimating the sample mean and standard deviation from the sample size, median, range and/or interquartile range. BMC Med Res Methodol. 2014;14:135.

36. Ng SW, Popkin BM. Time use and physical activity: a shift away from movement across the globe. Obes Rev. 2012;13(8):659-80.

37. Buck C, Loyen A, Foraita R, Van Cauwenberg J, De Craemer M, Mac Donncha $C$, et al. Factors influencing sedentary behaviour: a system based analysis using Bayesian networks within DEDIPAC. PLoS One. 2019;14(1): e0211546.

38. Reitsma MB, Fullman N, Ng M, Salama JS, Abajobir A, Abate KH, et al. Smoking prevalence and attributable disease burden in 195 countries and territories, 1990-2015: a systematic analysis from the global burden of disease study 2015. Lancet. 2017;389(10082):1885-906.

\section{Publisher's Note}

Springer Nature remains neutral with regard to jurisdictional claims in published maps and institutional affiliations.

Ready to submit your research? Choose BMC and benefit from:

- fast, convenient online submission

- thorough peer review by experienced researchers in your field

- rapid publication on acceptance

- support for research data, including large and complex data types

- gold Open Access which fosters wider collaboration and increased citations

- maximum visibility for your research: over $100 \mathrm{M}$ website views per year

At $\mathrm{BMC}$, research is always in progress.

Learn more biomedcentral.com/submissions 